\title{
Chronic kidney disease in the type 2 diabetic patients: prevalence and associated variables in a random sample of 2642 patients of a Mediterranean area
}

Gabriel Coll-de-Tuero ${ }^{1}$, Manel Mata-Cases ${ }^{2}$, Antonio Rodriguez-Poncelas ${ }^{3 *}$, Josep MA Pepió ${ }^{4}$, Pilar Roura ${ }^{5}$, Belen Benito ${ }^{6}$, Josep Franch-Nadal ${ }^{7}$ and Marc Saez ${ }^{8}$

\begin{abstract}
Background: Kidney disease is associated with an increased total mortality and cardiovascular morbimortality in the general population and in patients with Type 2 diabetes. The aim of this study is to determine the prevalence of kidney disease and different types of renal disease in patients with type 2 diabetes (T2DM).

Methods: Cross-sectional study in a random sample of 2,642 T2DM patients cared for in primary care during 2007. Studied variables: demographic and clinical characteristics, pharmacological treatments and T2DM complications (diabetic foot, retinopathy, coronary heart disease and stroke). Variables of renal function were defined as follows: 1) Microalbuminuria: albumin excretion rate $>30 \mathrm{mg} / \mathrm{g}$ or $3.5 \mathrm{mg} / \mathrm{mmol}$, 2) Macroalbuminuria: albumin excretion rate $>300 \mathrm{mg} / \mathrm{g}$ or $35 \mathrm{mg} / \mathrm{mmol}, 3$ ) Kidney disease (KD): glomerular filtration rate according to Modification of Diet in Renal Disease $<60 \mathrm{ml} / \mathrm{min} / 1.73 \mathrm{~m}^{2}$ and/or the presence of albuminuria, 4) Renal impairment (RI): glomerular filtration rate $<60 \mathrm{ml} / \mathrm{min} / 1.73 \mathrm{~m}^{2}$, 5) Nonalbuminuric Rl: glomerular filtration rate $<60 \mathrm{ml} / \mathrm{min} / 1.73 \mathrm{~m}^{2}$ without albuminuria and, 5) Diabetic nephropathy (DN): macroalbuminuria or microalbuminuria plus diabetic retinopathy.

Results: The prevalence of different types of renal disease in patients was: $34.1 \% \mathrm{KD}, 22.9 \% \mathrm{RI}, 19.5 \%$ albuminuria and $16.4 \%$ diabetic nephropathy (DN). The prevalence of albuminuria without RI (13.5\%) and nonalbuminuric RI (14.7\%) was similar. After adjusting per age, BMI, cholesterol, blood pressure and macrovascular disease, RI was significantly associated with the female gender (OR 2.20; Cl 95\% 1.86-2.59), microvascular disease (OR 2.14; Cl 95\% 1.8-2.54) and insulin treatment (OR 1.82; Cl 95\% 1.39-2.38), and inversely associated with HbA1c (OR 0.85 for every $1 \%$ increase; Cl 95\% 0.80-0.91). Albuminuria without RI was inversely associated with the female gender (OR 0.27; Cl 95\% 0.21-0.35), duration of diabetes (OR 0.94 per year; Cl 95\% 0.91-0.97) and directly associated with HbA1c (OR 1.19 for every 1\% increase; Cl 95\% 1.09-1.3).

Conclusions: One-third of the sample population in this study has KD. The presence or absence of albuminuria identifies two subgroups with different characteristics related to gender, the duration of diabetes and metabolic status of the patient. It is important to determine both albuminuria and GFR estimation to diagnose KD.
\end{abstract}

Keywords: Kidney disease, Renal impairment, Albuminuria, Diabetic nephropathy

\footnotetext{
* Correspondence: arpon@comg.cat

${ }^{3}$ Primary Healthcare Center Anglès, Research Unit, I.A.S, Salt, Spain

Full list of author information is available at the end of the article
} 


\section{Background}

The concept of kidney disease is based on the presence of albuminuria and/or impaired renal function that lasts for more than three months [1]. Kidney disease is associated with an increased total mortality and cardiovascular morbimortality in the general population [2] and in patients with Type 2 diabetes (T2DM) [3]. Patients with T2DM with renal impairment have an increased mortality risk, specially a higher risk of cardiovascular (CV) death, when compared to other diabetic patients without renal impairment [4]. Moreover, albuminuria predicts an increased risk of myocardial infarction, stroke, CV death, total death and heart failure in patients with T2DM in comparison with non-diabetic patients [5]. However, not all T2DM patients with renal impairment have albuminuria [6]. Therefore, the National Kidney Foundation (NKF) [1] recommends the determination of plasma creatinine to estimate glomerular filtration rate (GFR), because renal impairment and albuminuria are independently associated with strokes [7]. The simultaneous presence of renal impairment and albuminuria is associated with an increased risk of $\mathrm{CV}$ morbidity, increased risk of total mortality, and progression of renal disease [8].

During a 15-year follow-up, the United Kingdom Prospective Diabetes (UKPDS) study showed that $5 \%$ of the patients with T2DM had a 2-fold increase in creatinine levels, $20 \%$ had macroalbuminuria defined as a urinary albumin concentration $\geq 300 \mathrm{mg} / \mathrm{l}, 40 \%$ developed renal impairment, $45 \%$ developed microalbuminuria defined as a urinary albumin concentration $50-299 \mathrm{mg} / \mathrm{l}$ and 75\% experienced a CV event [9]. Early detection of kidney disease in patients with diabetes is important because close monitoring of cardiovascular risk factors, and specific drugs acting on the renin-angiotensin system slow down the progression of renal disease [10].

There have been several reports on the prevalence of kidney disease and forms of renal disease in patients with T2DM of Mediterranean countries [11-13]. Only one study has been conducted in a randomly selected population sample in Spain [14], and they characterized renal impairment regardless of albuminuria. The main objective of this study was to determine the prevalence of kidney disease in patients with T2DM, forms of renal disease (renal impairment, albuminuria, renal impairment without albuminuria, nonalbuminuric renal impairment and diabetic nephropathy) and associated variables in a large sample of patients in primary care.

\section{Methods}

Study design and organization The Continuous Quality Improvement Gedaps program gathered information from primary care centres on the clinical markers and health outcomes a sample of patients. A detailed description of the evaluation methodology has been previously described [15]. During the last evaluation in 2007, several meetings around Catalonia were conducted to encourage the involvement in the study regardless of participation in previous evaluations, and to present changes in the data entry using a webpage (http://www.redgdps.org/index.php? idregistro $=259$ ).

Health providers were instructed to obtain a random sample from the medical records of patients with T2DM with more than six months follow-up from diagnosis. A total sample of 5 patients multiplied by the number of basic care units (physician/nurse) with a minimum of 30 patients per centre was required. The exclusion criteria were as follows: type 1 diabetes mellitus; follow-up exclusively conducted by an endocrinologist; and short life expectancy (terminal patients or those who received home care). Only patients with plasma creatinine available were included for the current study.

Due to the retrospective nature of the study, based only on clinical records, patients were not required to give written informed consent. To assure anonymity data were collected and recorded using two different files: one included demographic variables and the other one clinical variables linked by a consecutive record number. The study design and the GCQI program were presented and approved by the Consell Assessor de la Diabetes (Advisory Board on Diabetes) of the Health Departament of the Autonomous Government in Catalunya that acted as Institutional Review Board.

Study population The following demographic and clinical characteristics were compared: age, gender, weight, height, BMI, blood pressure, HbAlc, creatinine, total cholesterol, HDL cholesterol, albuminuria, duration of diabetes (in years), estimated cardiovascular risk according to the Framingham equation calibrated to the Spanish population [16] (threshold $>10 \%$ at 10 years), antidiabetic treatment, antihypertensive treatment, lipid-lowering therapy, antiplatelet therapy, and smoking status. Obesity was considered if the BMI was greater than $30 \mathrm{~kg} / \mathrm{m}^{2}$. We found 1164 type 2 diabetic patients who had no available albuminuria. Figure 1 shows the samples used to calculate the prevalence of the different forms of kidney disease.

The following outcomes were considered: diabetic foot (ulcers and amputations), retinopathy, coronary heart disease (CHD, including angina), and stroke (including transient ischemic attack). Two composite variables including all microvascular complications (albuminuria and/or retinopathy) and macrovascular complications (CHD and/or stroke) were separately created. All collected data included the last value recorded in the medical records during 2007.

NKF [1] defines chronic kidney disease by the persistence of a low GFR and/or albuminuria during a period of at least three months. In our study, since no previous measurement of creatinine or albuminuria was available, 
Random sample of patients with T2DM included in the 2007 Gedaps evaluation

$(\mathrm{n}=3150)$

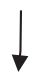

Type 2 diabetic patients with creatinine available $\longrightarrow$ Prevalence of renal impairment

$(n=2,642)$

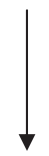

Type 2 diabetic patients with available urinary albumin excretion rate

$(\mathrm{n}=1,478)$

Prevalence of kidney disease according to KDIGO worgroup, nonalbuminuric renal impairment and albuminuria alone.

Figure 1 Flow-chart of study.

it was impossible to know whether or not these conditions had persisted longer than three months. Thus, we defined kidney disease based and renal impairment based on a single determination. Serum creatinine was measured on a multiparameter analyzer (Cobas 711, Roche Modular System, Indianapolis, IN, USA) by the Jaffé Method with bichromatic measurements according to the manufacturer's specifications. Albuminuria was measured by inmmunoturbidimetry on a Cobas 400 analyzer (Roche, Indianapolis, IN, USA).

The GFR was calculated using the equation previously published by the MDRD study group [17]. Variables of renal function were defined as follow: 1) Microalbuminuria: Albumin excretion rate (AER) $>30 \mathrm{mg} / \mathrm{g}(3.5 \mathrm{mg} / \mathrm{nmol}), 2)$ Macroalbuminuria: AER > $300 \mathrm{mg} / \mathrm{g}$ ( $35 \mathrm{mg} / \mathrm{nmol})$, 3) Kidney disease: GFR $<60 \mathrm{ml} / \mathrm{min} / 1.73 \mathrm{~m} 2$ and/or the presence of micro or macroalbuminuria, 4) Renal impairment: GFR $<60 \mathrm{ml} / \mathrm{min} / 1.73 \mathrm{~m} 2,5)$ Nonalbuminuric renal impairment: GFR $<60 \mathrm{ml} / \mathrm{min} / 1.73 \mathrm{~m}^{2}$ without micro or macroalbuminuria and, 5) Diabetic nephropathy (DN): macroalbuminuria or microalbuminuria plus diabetic retinopathy [18].

Patients with available creatinine and UAER were also classified according to the recent proposal of KDIGO workgroup [19].

Statistical analysis Quantitative variables were described using means and standard deviations. Categorical variables were summarised using absolute and relative frequencies (i.e., percentages). Bivariate relationships between categorical variables were tested using non-parametric chi-squared tests. Bivariate relationships between categorical and quantitative variables were assessed using ANOVA tests (one factor). Descriptive statistics and bivariate inferences were performed using the SPSS (v. 15) statistical program. The multivariate analyses of variables associated with different types of kidney disease in patients with T2DM were assessed by means of logistic regressions. The variables for the adjustment were selected on the basis of significant bivariate relationships. Response variables were assigned a value of 1 when the particular type of kidney disease (i.e., renal impairment, DN and kidney disease) occurred, and patients without any type of kidney disease were assigned a value of 0 . The estimation of the logistic regressions was performed using the $\mathrm{R}$ freeware statistical package (version 2.11.1).

\section{Results}

\section{Sample characteristics}

From a total sample of 3150 patients with T2DM included in the 2007 Gedaps evaluation, we included 2,642 patients who have a plasma creatinine available. Mean age was 68 years (SD 11.6), and 51.5\% of the patients were men. The average duration of diabetes was 7 years (SD 5.6). The mean HbA1c was 6.84\% (SD 1.46), and $67.6 \%$ of patients had an HbA1c value less than or equal to $7 \%$. The mean blood pressure was 137/ $76 \mathrm{mmHg}$. Table 1 shows the main characteristics of the population. To rule out a bias attributable to patients without albuminuria data, we compared a subgroups with available albuminuria data (1,478 patients), and to the 1,164 patients not having albuminuria data. Of all variables compared (age, gender, years of evolution, HbA1c, systolic blood pressure, diastolic blood pressure and creatinine), only age showed differences (67.59 vs 68.58; $\mathrm{p}=0.03)$. 
Table 1 Characteristics of the sample of patients with type 2 diabetes $(n=2,642)$

\begin{tabular}{|c|c|c|c|c|}
\hline & Total & Men & Women & $p$ value \\
\hline Age, years; mean (SD) & $68.06(11.60)$ & $66.81(11.63)$ & $69.31(11.59)$ & $<0.001$ \\
\hline Gender,n (\%) & 2642 & $1361(51.5)$ & $1281(48.5)$ & ns \\
\hline Years of diabetes duration, mean (SD) & $7.05(5.60)$ & $6.58(5.06)$ & $7.39(6.04)$ & $<0.001$ \\
\hline Diabetes duration 5-10 years, n (\%) & $803(30.4)$ & $413(30.4)$ & $390(30.5)$ & ns \\
\hline Diabetes duration > 10 years, $\mathrm{n}(\%)$ & $497(18.8)$ & $231(17.0)$ & $266(20.8)$ & $<0.05$ \\
\hline $\mathrm{BP}, \mathrm{mmHg}$,mean (SD) & $137.23 / 76.52(14.60 / 9.05)$ & $136.98 / 76.49(14.68 / 9.10)$ & 137.08/76.43 (14.71/8.89) & ns SBP ns DBP \\
\hline Hypertension,n (\%) & $1847(69.9)$ & $894(65.6)$ & $953(74.3)$ & $<0.001$ \\
\hline $\mathrm{BP} \leq 140 / 90 \mathrm{mmHg}, \mathrm{n}(\%)$ & $1896(71.7)$ & $976(71.7)$ & $920(71.8)$ & ns \\
\hline $\mathrm{BP} \leq 130 / 80 \mathrm{mmHg}, \mathrm{n}(\%)$ & 915 (34.6) & $460(33.8)$ & $455(35.5)$ & ns \\
\hline HbA1c, mean (SD) & $6.84(1.46)$ & $6.83(1.47)$ & $6.85(1.44)$ & ns \\
\hline $\mathrm{HbA} 1 \mathrm{c} \leq 7 \%, \mathrm{n}(\%)$ & $1786(67.6)$ & $920(67.6)$ & $866(67.6)$ & ns \\
\hline $\mathrm{HbA} 1 \mathrm{c} \leq 8 \%, \mathrm{n}(\%)$ & $2319(87.7)$ & $1182(86.8)$ & $1137(88.7)$ & ns \\
\hline Total cholesterol,mg/dl,mean (SD) & $194.33(38.41)$ & $188.06(38.45)$ & $201.00(37.25)$ & $<0.001$ \\
\hline Non-HDL cholesterol, mg/dl,mean (SD) & $144,10(37.44)$ & $140.63(37.72)$ & $148.10(36.65)$ & $<0.001$ \\
\hline Non-HDL cholesterol < 130 mg/dl, n (\%) & $1007(38.1)$ & $592(43.5)$ & $415(32.4)$ & $<0.001$ \\
\hline Non-HDL cholesterol < 160 mg/dl, n (\%) (1) & $1802(68.2)$ & $957(70.3)$ & $845(66.0)$ & 0.025 \\
\hline Obesity, n (\%) & $1118(42.3)$ & $471(34.6)$ & $647(50.5$ & $<0.001$ \\
\hline Tobacco habit, n (\%) & $365(13.8)$ & $299(22.0)$ & $66(5.1)$ & $<0.001$ \\
\hline Creatinine, mg/dl (SD) & $1.21(1.03)$ & $1.30(1.12)$ & $1.10(0.92)$ & $<0.001$ \\
\hline GFR, $\mathrm{mil} / \mathrm{min} / 1.73 \mathrm{~m}^{2}$ (SD) & $76.30(32.79)$ & $79.73(29.48)$ & $72.71(35.67)$ & $<0.001$ \\
\hline Macrovascular disease,n (\%) (1) & $460(17.4)$ & $275(20.2)$ & $185(14.4)$ & $<0.001$ \\
\hline $\mathrm{CHD}, \mathrm{n}(\%)$ & $329(12.4)$ & $197(14.5)$ & $132(10.3)$ & 0.014 \\
\hline Stroke,n (\%) & $188(7.1)$ & $102(7.5)$ & $86(6.7)$ & ns \\
\hline Diabetic foot, n (\%) (2) & $100(5.0)$ & $48(4.6)$ & $52(5.3)$ & ns \\
\hline Microvascular disease (3) & $475(32.1)$ & $260(34.1)$ & $215(30.0)$ & ns \\
\hline Albuminuria, n (\%) (3) & $288(19.5)$ & $184(24.1)$ & $104(14.5)$ & $<0.001$ \\
\hline Diabetic retinopathy, n (\%) & $227(15.3)$ & $113(14.8)$ & $114(16.0)$ & ns \\
\hline ACEI/ARB treatment, $\mathrm{n}(\%)$ & $1453(54.9)$ & $741(54.5)$ & $712(55.5)$ & ns \\
\hline $\begin{array}{l}\text { Calibrated Framingham cardiovascular risk } \\
\text { equation }>10 \%, \mathrm{n}(\%)\end{array}$ & $240(9.1)$ & $194(14.2)$ & $46(3.6)$ & $<0.001$ \\
\hline
\end{tabular}

(1) Coronary heart disease (CHD) and/or stroke; (2) Ulcers and/or amputations, $n=2,000$, men 1030, women 970; (3) Albuminuria and/or diabetic retinopathy, $\mathrm{n}=1478$, men 761, women 717 .

$B P$ : blood pressure, $H D L$ : high density lipoprotein, GFR: glomerular filtration rate, $A C E l$ : angiotensin converting enzyme inhibitor, $A R B$ : angiotensin receptor blocker.

\section{Prevalence of kidney disease}

The prevalence of different types of renal disease was: $34.1 \%$ for kidney disease, $22.9 \%$ for renal impairment, $19.5 \%$ for albuminuria and $16.4 \%$ for diabetic nephropathy. Renal impairment according to the MDRD equation was found in 606 patients (22.9\%) of whom 296 (11.2\%) showed an elevated serum creatinine value $(>123.76 \mu \mathrm{mol} / \mathrm{dl}$ in women and > $132.6 \mu \mathrm{mol} / \mathrm{dl}$ in men). Moreover, 382 patients (14.5\%) showed an estimated GFR between 30 and $59 \mathrm{ml} / \mathrm{min} / 1.73 \mathrm{~m} 2$, and 224 patients $(8.4 \%)$ of the total showed an estimated GFR less than $30 \mathrm{ml} / \mathrm{min} / 1.73 \mathrm{~m} 2$. Additional file 1: Table S2 shows the prevalence of kidney disease as defined by the KDIGO workgroup [19] in 1478 T2DM patients in which the creatinine and albuminuria was available. Among patients with RI, 71.1\% were nonalbuminuric.

There were significant differences in gender among the forms of kidney disease. Women had a significantly higher prevalence of kidney disease and renal impairment, and men had a higher prevalence of albuminuria and DN. Significant differences in the forms of kidney disease were also found with the duration of diabetes (Table 2).

Figure 2 shows that the prevalence of renal impairment was similar in both sexes until age 70 and that the prevalence of renal impairment was significantly higher in women after age 70 . In contrast, the prevalence of albuminuria was higher in men in all age ranges. 
Table 2 Prevalence of different types of kidney disease stratified by gender and years of Type 2 diabetes duration

\begin{tabular}{llllllll}
\hline & Total & Men & Women & $\mathbf{p}$ value & $<\mathbf{5}$ years diabetes duration & $\geq \mathbf{5}$ years diabetes duration & $\mathbf{p}$ value \\
\hline $\mathbf{K D}, \mathbf{n}(\%)(\mathbf{1})$ & $505(34.1)$ & $235(15.9)$ & $270(18.2)$ & 0.028 & $327(22.1)$ & $178(12.0)$ & $394(14.9)$ \\
$\mathbf{R I}, \mathbf{n}(\%)(\mathbf{2})$ & $606(22.9)$ & $239(9.0)$ & $367(13.9)$ & $<0.001$ & $212(8.0)$ & $181(12.2)$ & $<0.001$ \\
$\begin{array}{l}\text { Diabetic nephropathy, } \\
\mathbf{n}(\%)(\mathbf{1})\end{array}$ & $243(16.4)$ & $139(9.4)$ & $104(7.0)$ & 0.06 & $62(4.2)$ & $191(12.9)$ & $<0.001$ \\
Albuminuria, $\mathbf{n}(\%)(\mathbf{1})$ & $288(19.5)$ & $184(12.4)$ & $104(7.1)$ & $<0.001$ & $97(6.6)$ & $<0.001$
\end{tabular}

KD: kidney disease. Albuminuria and/or altered GFR; RI: renal impairment. GFR $<60 \mathrm{mil} / \mathrm{min} / 1.73 \mathrm{~m}^{2}$. Diabetic nephropathy: Albuminuria $>300 \mathrm{mg} / \mathrm{gr}$ or albuminuria $30-300 \mathrm{mg} / \mathrm{gr}$ and retinopathy. Albuminuria: urinary albumin excretion rate $>30 \mathrm{mg} / \mathrm{gr}$.

(1) $n=1478 ;(2) n=2642$.

\section{Types of kidney disease and associated variables}

Among the 1,478 patients with T2DM who had available data for calculating both GFR and albuminuria, patients with albuminuria without renal impairment and nonalbuminuric renal impairment were compared. The prevalence of albuminuria without renal impairment (albuminuria alone) (13.5\%) and nonalbuminuric renal impairment (14.7\%) was similar. Relative to albuminuric patients without renal impairment, the patients with nonalbuminuric renal impairment were significantly older and with more probability to be women; they had a longer T2DM duration, lower prevalence of obesity, lower diastolic BP and lower HbA1c; and had a lower prevalence of smoking, macrovascular disease and ischemic heart disease (Table 3).

Adjusted multivariate analysis shows that those T2DM patients with renal impairment have a different profile to those with albuminuria alone. The variables associated with the difference between both types of $\mathrm{KD}$ were: gender, years of diabetes duration and HbA1c (Table 4). Diabetic nephropathy patients only show gender differences and increased use of insulin.

\section{Discussion}

Within a random sample of patients with T2DM living in Catalonia (Spain), the prevalence of kidney disease, renal impairment, albuminuria and diabetic nephropathy was found to be $34.1 \%, 22.9 \%, 19.5 \%$ and $16.4 \%$, respectively. The prevalence of albuminuria without renal impairment and nonalbuminuric renal impairment was $13.5 \%$ and $14.7 \%$, respectively. In the case of renal impairment, the estimation of GFR identified an additional $13.4 \%$ of patients with T2DM with renal impairment who would not have been diagnosed only with the measurement of plasma creatinine. The GFR estimation allowed the detection of $20.6 \%$ of patients with kidney disease in addition to the $13.5 \%$ of patients with albuminuria alone. When using strict criteria to define DN [18], the prevalence decreased from 19.5\% (albuminuria) to $16.3 \%$ (albuminuria and diabetic retinopathy). Thus, the difference between these two approaches was only $3.1 \%$. In our study, as recommended by the NKF-K/ DOQI the same cutoff for normal AER has been used for both sexes. In contrast, the European Societies of Cardiology and Hypertension [20] recommend adopting

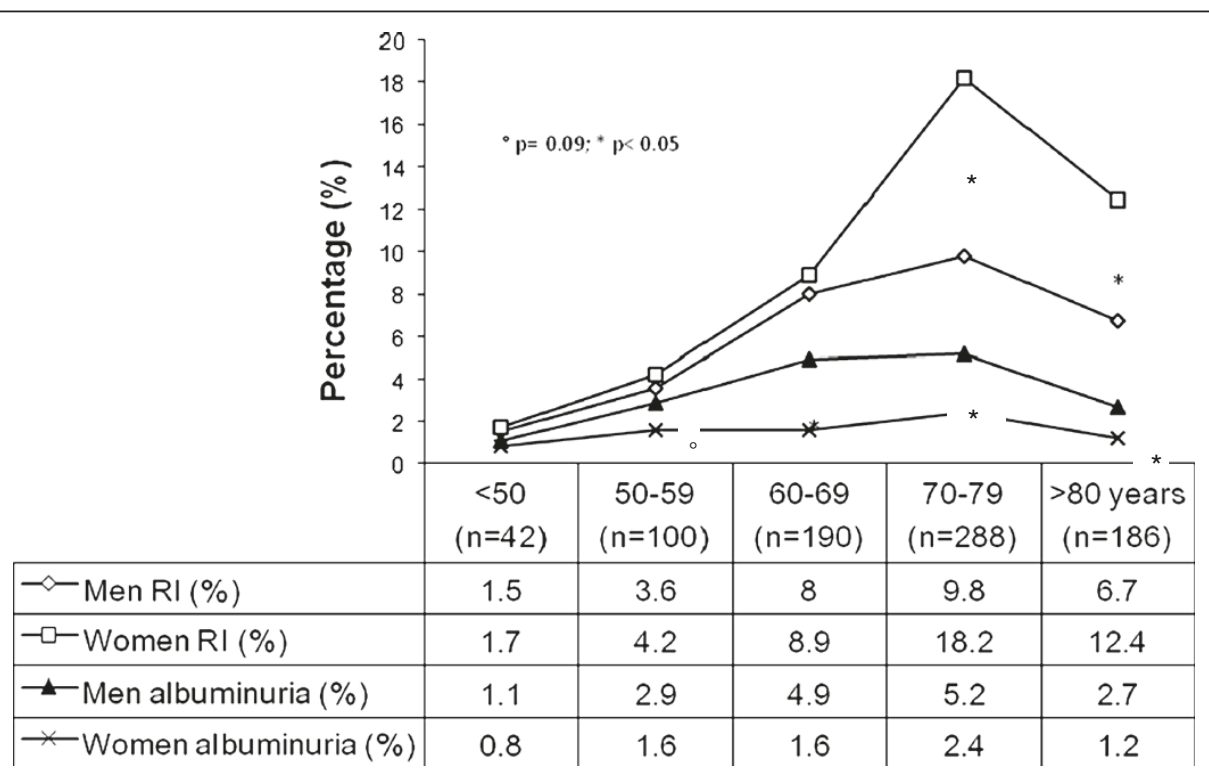

Figure 2 Prevalence of renal impairment and albuminuria alone stratified according to age and gender $(\mathbf{n}=\mathbf{8 0 6})$. 
Table 3 Prevalence of different types of chronic kidney disease and associated variables in the 1478 diabetic patients in wich CRI and albuminuria data were available

\begin{tabular}{|c|c|c|}
\hline & Albuminuria without renal impairment & Nonalbuminuric renal impairment \\
\hline $\mathrm{n},(\%)$ & $200(13.5)$ & $217(14.7)$ \\
\hline Age, mean (SD) & $67.49(11.89)$ & $72.35(9.94)^{\mathbf{a}}$ \\
\hline Gender, men (\%) & $137(68.5)$ & $75(34.6)^{\mathbf{a}}$ \\
\hline Type 2 DM duration, years (SD) & $7.13(4.89)$ & $8.41(6.43)^{\mathbf{a}}$ \\
\hline Obesity, n (\%) & 75 (44.4) & $79(39.3)^{\mathbf{a}}$ \\
\hline $\mathrm{BP}, \mathrm{mmHg}(\mathrm{SD})$ & $139.79 / 77.79(15.22 / 9.35)$ & $138.12 / 75.38(14.22 / 8.72)^{\mathbf{b}}$ \\
\hline HbA1c, mean (SD) & $7.27(1.61)$ & $6.68(1.42)^{\mathbf{a}}$ \\
\hline Total cholesterol, mean (SD) & $187.74(37.38)$ & $193.17(36.66)$ \\
\hline Non-HDL cholesterol, mg/dl, mean (SD) & $141.75(34.89)$ & $141.81(35.75)$ \\
\hline Creatinine, mg/dl (SD) & $0.87(0.17)$ & $2.38(1.60)^{\mathbf{a}}$ \\
\hline GFR, $\mathrm{mil} / \mathrm{min} / 1.73 \mathrm{~m}^{2}(\mathrm{SD})$ & $92.49(58.24)$ & $36.55(19.28)^{\mathbf{a}}$ \\
\hline Tobacco, n (\%) & $34(18.1)$ & $15(7.0)^{\mathbf{b}}$ \\
\hline Macrovascular disease, $\mathbf{n}(\%)$ & $46(23.8)$ & $33(15.4)^{\mathbf{a}}$ \\
\hline CHD,n (\%) & $37(19.2)$ & $21(9.8)^{\mathbf{a}}$ \\
\hline Stroke, $\mathbf{n}(\%)$ & $10(5.2)$ & $15(6.9)$ \\
\hline Diabetic retinopathy, n (\%) & $23(20.2)$ & $25(18.9)$ \\
\hline Insulin treatment, $\mathbf{n}(\%)$ & $43(22.0)$ & $43(19.9)$ \\
\hline Calibrated Framingham CV risk eq. $>10 \%, \mathrm{n}(\%)$ & $14(10.4)$ & $7(6.3)$ \\
\hline
\end{tabular}

$B P$ : blood pressure; $H D L$ : high density lipoprotein, GFR: glomerular filtration rate, CHD: coronary heart disease, $C V$ : cardiovascular RI: renal impairment. Albuminuria without RI vs. Nonalbuminuric RI: ${ }^{\mathbf{a}} \mathrm{p}<0.001 ;{ }^{\mathbf{b}} \mathrm{p}<0.05$.

different normal values according to gender $(<31 \mathrm{mg} / \mathrm{g}$ or $3.5 \mathrm{mg} / \mathrm{mmol}$ for men and $<22 \mathrm{mg} / \mathrm{g}$ or $2.5 \mathrm{mg} / \mathrm{mmol}$ for women). So, $\mathrm{i}$ is possible that if we had used the European criteria, the prevalence of albuminuria would have been similar to the prevalence obtained by [12] in a similar cohort: $20.6 \%$.

Previous studies have shown that renal impairment prevalence is between 10.2 (sample of T2DM patients in China) [21] and 36\% [22]. Most studies have found a prevalence between 15 and 30\% [12-14,23-26] depending on ethnic and demographic characteristics of the samples such as age, gender and BMI [27]. The prevalence of renal impairment in the Mediterranean population has been shown to be between 16.6 [12] and 31.3\% [13]. These differences may be due to younger patients and lower percentage of women in the first study, and higher percentage of women in the second study. The prevalence of albuminuria in our study (19.5\%) was lower than in other studies, ranging from 31.7 [12] to 61\% [28]. This difference may be attributed to a greater number of younger obese men. In our study, the majority (71.1\%) of T2DM patients with renal impairment had nonalbuminuric renal

Table 4 Multivariate analysis of types of kidney disease and associated variables in type 2 diabetic patients

\begin{tabular}{|c|c|c|c|}
\hline & Renal impairment OR (Cl 95\%) & Nonalbuminuric RI OR (CI 95\%) & Diabetic nephropathy OR (CI 95\%) \\
\hline Gender (men) women & $2.20(1.86-2.54)$ & $0.27(0.21-0.35)$ & $0.56(0.40-0.78)$ \\
\hline Diabetes duration $(\leq 10)>10$ years & $1.43(1.18-1.74)$ & $0.66(0.48-1.08)$ & $0.80(0.54-1.19)$ \\
\hline D Diabetes duration For year & $1.03(1.02-1.05)$ & $0.94(0.91-0.97)$ & $0.97(0.94-1.1)$ \\
\hline ACEI/ARB treatment (No) Yes & $1.51(1.27-1.79)$ & $1.42(1.09-1.84)$ & $0.98(0.70-1.37)$ \\
\hline $\mathrm{BP}(\leq 130 / 80 \mathrm{mmHg})>130 / 80 \mathrm{mmHg}$ & $0.86(0.69-1.06)$ & $2.16(0.90-3.57)$ & $1.18(0.60-2.32)$ \\
\hline $\mathrm{HbA} 1 \mathrm{c}$ for each $1 \%$ of increase & $0.85(0.80-0.91)$ & $1.19(1.09-1.30)$ & $1.21(0.96-1.37)$ \\
\hline Insulin treatment (No) Yes & $1.82(1.39-2.38)$ & $1.42(1.08-1.84)$ & $4.17(2.33-7.44)$ \\
\hline Microvascular disease (No) Yes & $2.14(1.80-2.54)$ & - & - \\
\hline
\end{tabular}

In bold: $\mathbf{p}<\mathbf{0 . 0 1}$;

Adjusted also for age, body mass index, total cholesterol and non-HDL cholesterol, pulse pressure and macrovascular disease.

RI: renal impairment. Glomerular filtration rate $<60 \mathrm{mil} / \mathrm{min} / 1.73 \mathrm{~m}^{2}$. Diabetic nephropathy: albuminuria $>300 \mathrm{mg} / \mathrm{gr}$ or albuminuria $30-300 \mathrm{mg} / \mathrm{gr}$ plus retinopathy. Albuminuria: albuminuria $>30 \mathrm{mg} / \mathrm{gr}$.; $A C E l$ : angiotensin-converting enyme inhibitor; $A R B$ : angiotensin receptor blocker; $B P$ : blood pressure; $H b A 1 C$; glycated haemoglobin; Microvascular disease: albuminuria and/or diabetic retinopathy. 
impairment, which was slightly higher than to previously reported prevalence $[29,30]$. The profile of patients with nonalbuminuric renal impairment was different from those with albuminuria; there was a higher proportion of women in patients with nonalbuminuric renal impairment, and these patients were older, had a higher prevalence of obesity, had better metabolic control with less use of insulin, were less likely to smoke and had a lower prevalence of macrovascular disease. These two forms of kidney disease in patients with T2DM may correspond to different profiles [9]. Renal impairment reflects the filtration capacity of the kidney, and albuminuria is associated with kidney disease and generalized vascular inflammation. Renal impairment is associated with the duration of diabetes, and albuminuria has an inverse association where the process of glomerular involvement related to diabetes is slower than the appearance of microalbuminuria. However, both albuminuria and low GFR are independently associated with $\mathrm{CV}$ morbidity, $\mathrm{CV}$ mortality and total mortality [8].

The relationship between the mechanisms responsible for the development of albuminuria and renal impairment are not clear. In keeping with the most relevant studies published to date, our results show that nonalbuminuric RI is associated with female gender $[9,21,25,28,29]$. Nonalbuminuric RI was associated with the time elapsed from the diagnosis of diabetes, which was previously reported by Retnakavaran et al. [9]. However, Penno et al. [30] relate the duration of diabetes to both nonalbuminuric RI and albuminuria alone. Several authors showed that patients with nonalbuminuric RI have lower levels of HbA1c $[9,24]$ and lower prevalence of obesity [28] than those with albuminuria alone, as seen in our study. According to our results, the profile of T2DM patient with nonalbuminuric RI is a woman with a diagnose of diabetes made more than 10 years ago, low percentage of obesity, and good metabolic control measured by HbA1c. On the other hand, the patient with albuminuria alone is preferably male, with high percentage of obesity, and poor metabolic control. Diabetes duration was not significant in the latter case. There is no obvious explanation for this phenomenon other than that these diseases cause genderspecific vascular damage. We found only one study [30] comparing nonalbuminuric RI with albuminuria alone in T2DM patients. Their results are in agreement with ours in that male gender and HbAlc are associated with the presence of albuminuria alone. However, our study showed that the duration of diabetes and age are variables that differ in the two diseases whereas in the study of Penno et al. [30], age and duration of diabetes, were associated with the two forms of kidney disease. Our results may be helpful to discriminate between these two kidney diseases by taking into account the variables associated with each one of them. Several studies have reported a higher prevalence of microvascular damage (retinopathy and kidney disease) in hypertensive women $[31,32]$, but no data have been published showing a higher prevalence of microvascular damage in women with type 2 diabetes. A recent retrospective study showed that DN appeared significantly earlier among males than females [33]. This finding may explain the gender difference we found in our cross-sectional study based on a single observation. However, different phenotypic expressions depending on gender cannot be excluded.

A multivariate analysis showed a clear association between renal impairment and microvascular disease. In contrast, the bivariate analysis showed a clear association between albuminuria and macrovascular disease although the association disappeared in the multivariate analysis. It is possible that small vessels in women are more likely to develop damage than the small vessels in men. If this finding is confirmed in further studies, women with type 2 diabetes should be closely monitored. Another possibility is that the glomerular filtration rate in women estimated by the MDRD equation [34] underestimates the GFR. Thus, the prevalence of renal impairment would be falsely increased in women. Even if renal function in women, is underestimated by the MDRD equation, a recent study has reported the predictive value for coronary heart disease of the glomerular filtration rate calculated by the MDRD equation in a cohort of patients with high prevalence of diabetes when is added to the estimated risk according to Framingham [35]. In this study, the predictive effect was independent of albuminuria in women, but albuminuria was the variable with predictive value in men.

This study had several limitations. First, in terms of internal validity, it should be noted that there was a single measurement of GFR. Therefore, it was not possible to distinguish between patients with transient impairment of GFR and those with a persistent alteration. To distinguish between these patients, a reassessment of the GFR at 3 months would be necessary. A previous study has shown that kidney disease detected by a single determination is also associated with increased $\mathrm{CV}$ risk although the association contributes to a lesser degree than the two measurements [36]. Second, although the sampling was random and well reflected the patients with type 2 diabetes treated in primary care in Catalonia (Spain), the determination of plasma creatinine was not performed by a single laboratory. All reference laboratories have used Jaffé alkaline picrate method as a technique study, the variation of which is $1.31 \%$ [37]. For this reason, we believe that it is highly unlikely that these small differences in the estimation of creatinine may have influenced the results. Finally, due to the study design, patients not visited in primary care in the past year were excluded from the study as well as patients who had no creatinine measurement available during the study period. These patients 
may have had less control of their diabetes, blood pressure and dyslipidaemia, which may have been caused by a lower adherence to the prescribed treatment. Therefore, these patients may have introduced some selection bias into the study.

\section{Conclusions}

In summary, our results show that approximately onethird of type 2 diabetic patients in the Mediterranean area have kidney disease and that one-fourth of the patients have renal impairment, but only $10 \%$ would have been classified having renal impairment if the estimated glomerular filtration rate was not used. Moreover, one-fifth of the patients had albuminuria. T2DM patients with kidney disease have a different profile depending on the presence or absence of albuminuria or RI. Further studies are needed to identify the etiopathogenesis of these differences and may impact on the prevention and treatment of forms of kidney disease. Thus, it is important to determine AER and to estimate GFR to diagnose kidney disease and to initiate the appropriate treatment.

\section{Additional files}

Additional file 1: Table S2. Classification of patients with creatinine and albumin excretion rateavailable according to KDIGO 2009.

Additional file 2: List of participating investigators in the GEDAPS 2007 Evaluation.

\section{Abbreviations}

AER: Albumin excretion rate; CV: Cardiovascular; DN: Diabetic Nephropathy; GFR: Glomerular filtration rate; MDRD: Modification of Diet in Renal Disease; RI: Renal impairment; T2DM: Type 2 Diabetes Mellitus.

\section{Competing interest}

The authors declare that there is no conflict of interest associated with the manuscript.

\section{Authors' contributions}

G Coll de Tuero, M Mata-Cases, A Rodriguez-Poncelas and M Saez have participated in the conception and design, interpretation of data, drafting, revising and final approval of the work. JM Pepió, P Roura, B Benito and J Franch have participated in the conception and design, revising and final approval of the work. All authors read and approved the final manuscript.

\section{Acknowledgements}

All the members of the Gedaps group, physicians and nurses, without whose commitment to quality of care it would not have been possible to carry out this study. The list of participants could be seen in the Additional file 2.

\section{Author details}

${ }^{1}$ Primary Healthcare Center Anglès, Department of Medical Sciences, University of Girona, Girona, Spain. ${ }^{2}$ Primary Healthcare Center La Mina, Institut Catalá de la Salut, Barcelona, Spain. ${ }^{3}$ Primary Healthcare Center Anglès, Research Unit, I.A.S, Salt, Spain. ${ }^{4}$ Primary Healthcare Center Tortosa Oest, Tortosa, Spain. ${ }^{5}$ Departement of Medical Sciences, University Autònoma of Barcelona, Barcelona, Spain. ${ }^{6}$ Primary Healthcare Center, Raval Sud, Institut Catalá de la Salut, Barcelona, Spain. ${ }^{7}$ Primary Healthcare Center, Raval Sud, Barcelona, Spain. ${ }^{8}$ Applied Economics and Health(GRECS), Department of Economics, University of Girona, Girona, Spain.
Received: 27 March 2012 Accepted: 27 July 2012

Published: 20 August 2012

\section{References}

1. National Kidney Foundation: K/DOQI clinical practice guidelines for chronic kidney disease: Evaluation, classification and stratification. Am J Kidney Dis 2002, 39:46-64.

2. Keith DS Nichols GA, Gullion CM Brown JB, Smith DH: Longitudinal follow-up and outcomes among a population with chronic kidney disease in a large managed care organization. Arch Intern Med 2004, 164:659-663.

3. Adler Al, Stevens RJ, Manley SE, Bilous RW, Cull CA, Holman RR: Development and progression of nephropathy in type 2 diabetes: The United Kingdom Prospective Diabetes Study (UKPDS 64). Kidney Int. 2003, 63:225-32.

4. Nag S, Bilous R, Kelly W, Jones S, Roper N, Connolly V: All-cause and cardiovascular mortality in diabetic subjects increases significantly with reduced estimated glomerular filtration rate (eGFR): 10 years' data from the South Tees Diabetes Mortality study. Diabet Med. 2007, 24:10-7.

5. Gerstein HC, Mann JF, Yi Q, Zinman B, Dinneen SF, Hoogwerf B, Hallé JP, Young J, Rashkow A, Joyce C, Nawaz S, Yusuf S: HOPE Study Investigators. Albuminuria and risk of cardiovascular events, death, and heart failure in diabetic and nondiabetic individuals. JAMA 2001, 286:421-6.

6. Kramer HJ, Nguyen QD, Curhan G, Hsu CY: Renal insufficiency in the absence of albuminuria and retinopathy among adults with type 2 diabetes mellitus. JAMA. 2003, 289:3273-7.

7. Ovbiagele B: Impairment in Glomerular Filtration Rate or Glomerular Filtration Barrier and Occurrence of Stroke. Arch Neurol 2008, 65:934-938.

8. Ninomiya T, Perkovic V, de Galan BE, Zoungas S, Pillai A, Jardine M: Albuminuria and Kidney Function Independently Predict Cardiovascular and Renal Outcomes in Diabetes. J Am Soc Nephrol 2009, 20:1813-1821.

9. Retnakavan R, Cull CA, Thorne Kl, Adler Al, Holman RR: Diabetes 2006. Risk Factors for Renal Dysfunction in Type 2 Diabetes U.K. Prospective Diabetes Study 74. Diabetes 2006, 55:1832-1839.

10. Strippoli GFM, Craig M, Deeks JJ, Schena FP, Craig JC: Effects of angiotensin converting enzyme inhibitors and angiotensin II receptors antagonist on mortality and renal outcomes in diabetic nephropathy: systematic review. doi:10.1136/bmj.38237.585000.7C.

11. Tranche Iparraguirre S, Riesgo García A, Marín Iranzo R, Díaz González G, García Fernández A: Prevalence of "hidden" renal failure in the population suffering from type-2 diabetes. Aten Primaria 2005, 35:359.

12. Rodríguez-Poncelas A, Quesada Sabate M, Coll De Tuero G, Caula Ros J, Gelada-Batlle E, Gómez-Marcos MA, et al: Prevalence of occult chronic kidney disease and associated variables in a population of patients with type 2 diabetes. Med Clin (Barc) 2010, 134:239-245.

13. Lou Arnal LM, Campos Gutiérrez B, Cuberes Izquierdo M, Gracia García O, Turón Alcaine JM, Bielsa García S, et al: Prevalence of chronic kidney disease in patients with type 2 diabetes mellitus treated in primary care. Nefrologia 2010, 30:552-6.

14. Cea-Calvo L, Redon J, Martí-Canales JC, Lozano JV, Llisterri JL, Fernández-Pérez C: Prevalence of low glomerular filtration rate in the elderly population of Spain. The PREV-ICTUS study. Med Clin (Barc) 2007, 129:681-7.

15. Mata-Cases M, Roura-Olmeda P, Berengué-lglesias M, Birulés-Pons M, Mundet-Tuduri $X$, Franch-Nadal J: al. Fifteen years of continuous improvement of quality care of type 2 diabetes mellitus in primary care in Catalonia, Spain. Int J Clin Pract. 2012, 66(3):289-98.

16. Marrugat J, D'Agostino R, Sullivan L, Elosua R, Wilson P, Ordovas J, et al: An adaptation of the Framingham coronary risk function to southern Europe Mediterranean areas. J Epidemiol Comm Health 2003, 57:634-8.

17. Levey AS, Bosch JP, Lewis JB, Greene T, Rogers N, Roth DN: A more accurate method to estimate glomerular filtration rate from serum creatinine: A new prediction equation: Modification of Diet in renal Disease Study Group. Ann Intern Med. 1999, 30:461-70.

18. KDOQI Clinical Practice Guidelines and Clinical Practice Recommendations for Diabetes and Chronic Kidney Disease: 2012. http:// www.kidney.org/professionals/KDOQl/guideline_diabetes/guide1.htm (accessed June,2012) 
19. Levey AS, de Jong PE, Coresh J, El Nahas M, Astor BC, Matsushita K, Gansevoort RT, Kasiske BL, Eckardt KU: The definition, classification, and prognosis of chronic kidney disease: a KDIGO Controversies Conference report. Kidney Int. 2011, 80:17-28.

20. Mancia G, de Backer G, Dominiczak A, Cifkova R, Fagard R, Germano G, et al: 2007 Guidelines for the Management of Arterial Hypertension. The Task Force for the Management of Arterial Hypertension of the European Society of Hypertension (ESH) and of the European Society of Cardiology (ESC). $J$ Hypertens. 2007, 25:1105-1187.

21. Jia W, Gao X, Pang C, Hou X, Bao Y, Liu W, et al: Prevalence and risk factors of albuminuria and chronic kidney disease in Chinese population with type 2 diabetes and impaired glucose regulation Shanghai diabetic complications study (SHDCS). Nephrol Dial Transplant. 2009, 24:3724-31.

22. Maclsaac RJ, Tsalamandris C, Panagiotopoulos S, Smith TJ, McNeil KJ, Jerums G: Nonalbuminuric renal insufficiency in type 2 diabetes. Diabetes Care. 2004, 27:195-200.

23. Wall BM, Hardison RM, Molitch ME, Marroquin OC, McGill JB, August PA: High prevalence and diversity of kidney dysfunction in patients with type 2 diabetes mellitus and coronary artery disease: the BARI 2D baseline data. Am J Med Sci. 2010, 339:401-10.

24. Yokoyama H, Sone H, Oishi M, Kawai K, Fukumoto Y, Kobayashi M: Prevalence of albuminuria and renal insufficiency and associated clinical factors in type 2 diabetes: the Japan Diabetes Clinical Data Management study (JDDM15). Nephrol Dial Transplant. 2009, 24:1212-9.

25. Middleton RJ, Foley RN, Hegarty J, Cheung CM, McElduff P, Gibson JM, et al: The unrecognized prevalence of chronic kidney disease in diabetes. Nephrol Dial Transplant. 2006, 21:88-92.

26. Fagnani F, Souchet T, Labed D, Gaugris S, Hannedouche T, Grimaldi A: Management of hypertension and screening of renal complications by GPs in diabetic type 2 patients (France-2001). Diabetes Metab. 2003, 29:58-64.

27. Nair S, Mishra V, Hayden K, Lisboa PJ, Pandya B, Vinjamuri S, Hardy KJ, Wilding JP: The four-variable modification of diet in renal disease formula underestimates glomerular filtration rate in obese type 2 diabetic individuals with chronic kidney disease. Diabetologia; 2011. doi:10.1007/s00125-011-2085-9.

28. Al-Maskari F, El-Sadig M, Obineche E: Prevalence and determinants of microalbuminuria among diabetic patients in the United Arab Emirates. BMC Nephrol. 2008, 9:1. doi:10.1186/1471-2369-9-1.

29. Thomas MC, Maclsaac RJ, Jerums G, Weekes A, Moran J, Shaw JE, et al: Nonalbuminuric renal impairment in type 2 diabetic patients and in the general population (national evaluation of the frequency of renal impairment cO-existing with NIDDM [NEFRON] 11). Diabetes Care 2009, 32:1497-1502.

30. Penno G, Solini A, Bonora E, Fondelli C, Orsi E, Zerbini G, Trevisan R, Vedovato M, Gruden G, Cavalot F, Cignarelli M, Laviola L, Morano S, Nicolucci A, Pugliese G: Renal Insufficiency And Cardiovascular Events (RIACE) Study Group. Clinical significance of nonalbuminuric renal impairment in type 2 diabetes. J Hypertens. 2011, 29:1802-9.

31. De Tuero G: C, Barcelò MA and Saez M. Gender, socio-economic variables and target organ damage in new-diagnosed hypertensive patients. Blood Pressure 2009, 18:213-2.

32. Saitoh M, Nishimura H: T anaka T. Kondoh T. Gender-related differences in target organ damage in untreated patients with essential hypertension. Intern Med. 2006, 45:377-383.

33. Farag YMK, Al Wakeel JS: Diabetic nephropathy in the Arab Gulf Countries. Nephron Clin Prac 2011, 119:317-323.

34. Rigalleau V, Lasseur C, Perlemoine C, Barthe N, Raffaitin C, Liu C, et al: Estimation of glomerular filtration rate in diabetic subjects Cockcroft formula or Modification of Diet in Renal Disease study equation? Diabetes Care 2005, 28:838-43.

35. Shara NM, Wang H, Valaitis E, Pehlivanova M, Carter EA, Resnick H, et al: Comparison of estimated glomerular filtration rates and albuminuria in predicting risk of coronary heart disease in a population with high prevalence of diabetes mellitus and renal disease. Am J Cardiol. 2011, 107:399-405.

36. Weiner DE, Krassilnikova M, Tighiouart H, Salem DN, Levey AS, Sarnak MJ CKD classification based on estimated GFR over three years and subsequent cardiac and mortality outcomes: a cohort study. BMC Nephrol. 2009, 10:26. doi:10.1186/1471-2369-10-26.

37. Badiou S, Dupuy AM, Descamps B, Cristolead JP: Comparison between the enzymatic vitro assay for creatinine determination and three other methods adapted on the Olympus analyzer. J Clin Lab Anal 2003, 17:235-4.

doi:10.1186/1471-2369-13-87

Cite this article as: Coll-de-Tuero et al: Chronic kidney disease in the type 2 diabetic patients: prevalence and associated variables in a random sample of 2642 patients of a Mediterranean area. BMC Nephrology 2012 13:87.

\section{Submit your next manuscript to BioMed Central and take full advantage of:}

- Convenient online submission

- Thorough peer review

- No space constraints or color figure charges

- Immediate publication on acceptance

- Inclusion in PubMed, CAS, Scopus and Google Scholar

- Research which is freely available for redistribution 